\title{
Asbestos panelists accuse government of misusing science
}

$\mathrm{E}$ conomic and political interests are trumping science by threatening the federal government's release of a study of the health hazards of chrysotile asbestos, says the British chair of an expert panel appointed by Health Canada.

The delay of the report is an "annoying piece of needless government secrecy," says panel chair Trevor Ogden, editor-in-chief of the Annals of Occupational Hygiene. In an editorial published Sept, 9, 2008, Ogden accuses the Canadian government of misusing science.

With the government having now held onto the report for more than 6 months, Ogden questions whether the analysis will ever be released and wonders whether Canada is turning its back on "the best evaluation of science" concerning the risks of chrysotile asbestos.

Ogden penned the editorial to highlight "the problem of disguising economic and political decisions as scientific ones, using outdated or possibly one-sided evidence." to Canada, is highlighted in the current
"This problem, which is not unique

case of the Canadian government's delay in releasing an expert scientific panel report while at the same time taking a strong oppositional position on an international trade agreement directly related to the subject of the report," he wrote.

Ogden agreed to serve on the panel despite warnings from groups opposed to Canada's trade in asbestos because he supported Health Canada's decision to "do a good thing" by considering the science behind the cancer-causing potential of chrysotile. "Clearly it's been overtaken by other interests," he says.

Canada is the world's fifth-largest exporter of chrysotile asbestos, selling approximately 175000 tonnes worth about $\$ 112$ million to 80 nations, most of them in Asia. The industry, based near Thetford Mines, Quebec, creates 900 direct and 1000 indirect jobs, according to Natural Resources Canada 2006 figures.

In 2006, Canada blocked the addition of chrysotile asbestos to a list of substances that would, under the United Nations' Rotterdam Convention (see editorial, page 871), require coun-

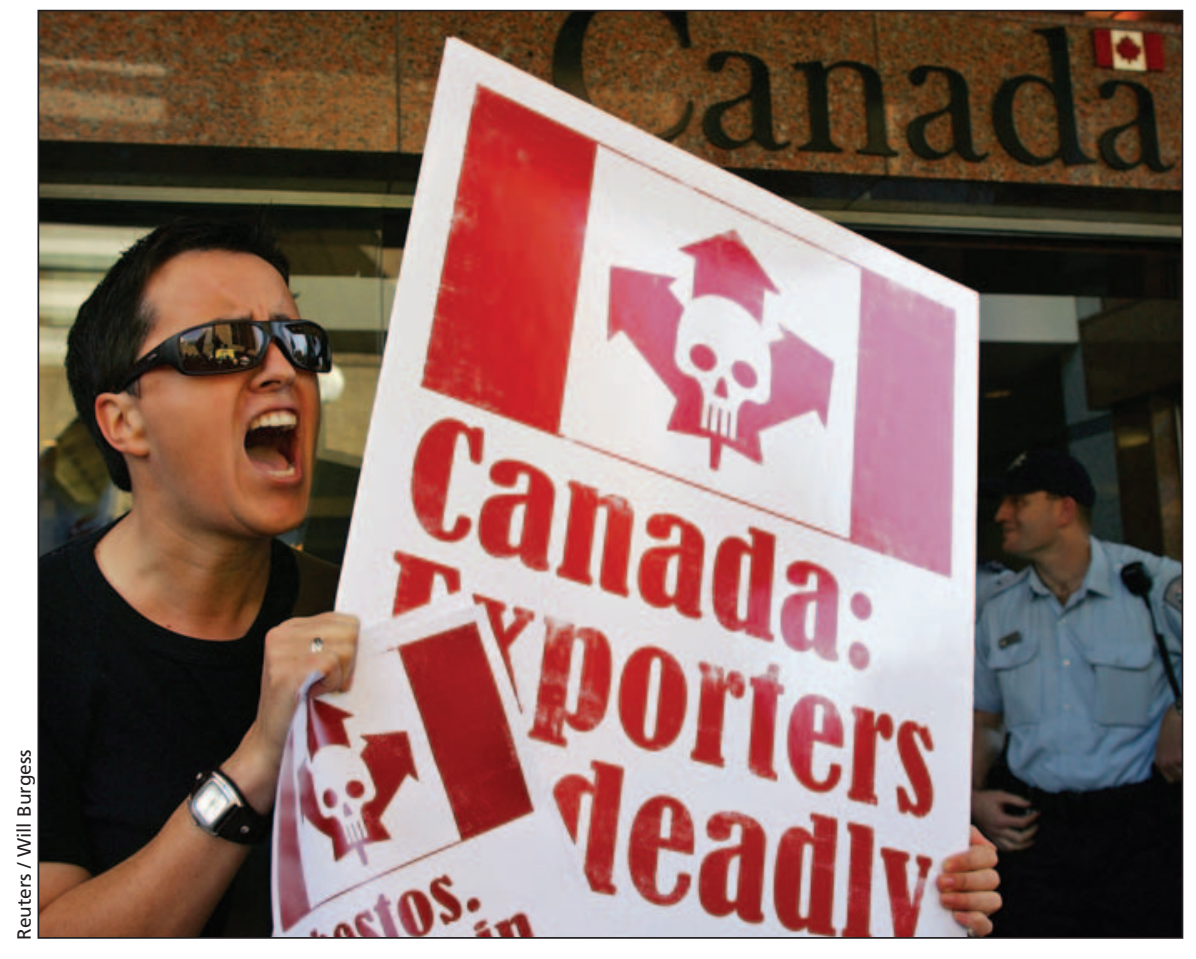

Protestors outside the Canadian Consulate General's office in Sydney, Australia, participating in a global demonstration against the Canadian government's ongoing support for the export of asbestos products. tries importing it to give what's known as prior informed consent. If chrysotile were on the list, Canada would have to prepare a document discussing any severe restrictions imposed on chrysotile for health or environmental reasons. Importing countries would then decide whether to import the substance, ban it, or restrict it.

In advance of an October 2008 meeting of parties to the Convention, Health Canada brought together international experts to determine the potency of exposure to chrysotile versus other forms of asbestos, and how best to estimate the risk of cancer from exposure to chrysotile asbestos.

The experts had divergent views.

Some members believe trade in chrysotile should be banned, and at least one member, toxicology consultant David Bernstein (see sidebar), argued that it should not.

The health debate revolves around whether chrysotile asbestos is as carcinogenic as amphibole asbestos, and what level of risk chrysotile poses for contracting mesothelioma and lung cancer.

The resulting panel discussions led to at least one "harsh" exchange between Bernstein and Bice Fubini, a chemistry professor at the University of Turin in Italy. The disagreement concerned the chemistry of the chrysotile fibres and how long Bernstein claims they remain in the lungs if inhaled, Fubini told CMAJ. "Certainly I did disagree with the description he gave of the whole chemistry of the fibres."

The panel's report consists of a consensus document, a chronology of the discussions and dissenting opinions. It does not make recommendations about whether chrysotile should be listed according to the Rotterdam requirements, or whether it should be banned, since panel members were asked only to look at the science of the substance's cancer-causing potential.

Panel members agreed with the findings of 2 previous literature reviews (Crit Rev Toxicol 2008;38[Suppl 1]:147 and Crit Rev Toxicol 2008;38[Suppl 1]:49-73), which concluded that chrysotile asbestos is less carcinogenic than amphibole asbestos when it comes 


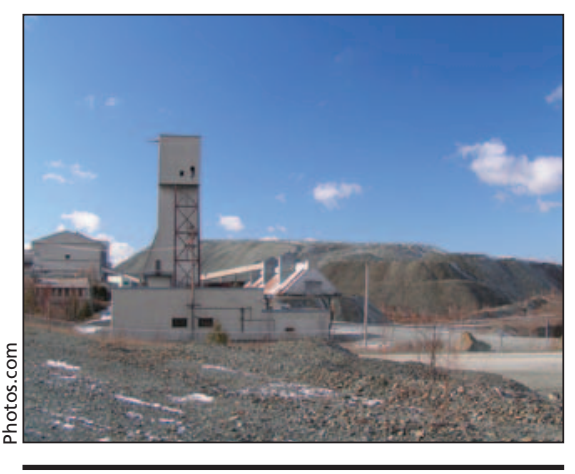

An abandoned asbestos mine.

to mesothelioma, Fubini says. But they also agreed that chrysotile is carcinogenic for lung cancer.

"It is certainly carcinogenic for lung cancer. It has to be banned. This is obvious, to me," says Fubini.

Another panel member called it "silly" for Health Canada to arrange and support the panel, and then not release the report.

"I don't believe there's anything particularly controversial in the report, but it certainly wouldn't help Canada's aims at the Rotterdam convention," says Nicholas de Klerk, head of the Department of Biostatistics and Genetic Epidemiology at the University of Western Australia.

Fubini surmises that the federal government fears that the public might not distinguish between mesothelioma and lung cancer. and therefore the report might negatively influence public opinion against mining and exporting asbestos. "Certainly there are huge economic interests in this whole subject," she says.

Health Canada received the panel report in March. In May, Ogden and American panelist Dr. Leslie Stayner went public with their concerns, accusing the government of breaking faith with the experts. New Democrat MP Pat Martin pressed Health Minister Tony Clement for the rationale behind delaying its release. Clement told Parliament that "we have received a report and we will be studying it. The government will be making its decision in due course."

Ogden speculates that the Oct. 14, 2008 federal election may have contributed to the report's delay but indicated that he believes trade considerations are foremost in federal minds. "I can only at- tribute it to the fact that Canada doesn't want it [the study] interfering with their position on the Rotterdam Convention."

Ogden also says delay of the report will have a long-term impact on the international community's willingness to sit on scientific panels. Canada is not going to continue to draw on the same scientific support and expertise if it continues to suppress or ignore scientific evidence, he warns. "The people involved on the panel would be very reluctant to do the same thing again." Laura Eggertson, Ottawa, Ont.

DOI:10.1503/cmaj.081532

\section{Asbestos panel member previously paid by industry}

A toxicologist serving on a panel of international experts that Health Canada commissioned to examine the health risks associated with chrysotile asbestos had been previously retained by industry giant Union Carbide, according to court documents CMAJ obtained.

David Bernstein, a toxicology consultant based in Geneva, served on the expert panel appointed by Health Canada to assess the relative carcinogenicity of chrysotile asbestos, which Canada exports. The report, delivered in March 2008, has not yet been released.

According to the transcript of a lawsuit in District Court in Ellis County, Texas, asbestos product manufacturer Union Carbide paid Bernstein 100000 Swiss francs, as well as an additional sum to conduct a study and run a laboratory to evaluate the disease-causing potential of chrysotile asbestos. In October 2007, Bernstein was called as an expert witness on asbestos in a lawsuit brought by Emma Maloney Martin against Quigley Company Inc. Bernstein was also paid previously by Canadian and Californian asbestos mining companies, and by the Canadian government and the Asbestos Institute, according to the transcript.

Until the early 1970s, Quigley sold products containing asbestos. Martin and other claimants have filed more than 171000 lawsuits against Quigley alleging that exposure to asbestos made them ill. Pfizer Inc. bought Quigley in 1968. Martin's lawyer contended that Bernstein received US\$400 623.20 from Union Carbide. During the trial, Bernstein testified that unlike amphibole asbestos, "the shorter chrysotile fibers are removed from the lung and they are not available to cause disease."

Typically, Health Canada requires potential members of its expert panels to fill out conflict-of-interest disclosure forms. CMAJ was unable to determine if Bernstein filled out such a form, because the department refused to release copies of the panel members' forms.

Bernstein declined to be interviewed, citing a confidentiality agreement he signed with Health Canada concerning the panel report.

Other panel members say Bernstein's views that chrysotile asbestos can be handled safely and does not cause disease were widely known, and resulted in some "harsh" discussions during panel proceedings. Panel chair Trevor Ogden says Health Canada intended to bring people with divergent views together to see if they could arrive at some consensus about how potently carcinogenic chrysotile asbestos is.

Bice Fubini, a chemistry professor at the University of Turin in Italy, says she disputed Bernstein's views about whether chrysotile asbestos breaks into pieces and can therefore be safely absorbed in the lungs. She was disturbed to learn about his previous relationship to the asbestos industry, particularly since she has known Bernstein for 18 years and has heard him speak at international conferences.

Commenting on Bernstein's previous contract with Union Carbide, Fubini said: "He never disclosed these links." Given the past link, Fubini says she doesn't think Bernstein was a correct choice for panel membership. 